\title{
The relationship between leadership, teamworking, structure, burnout and attitude to patients on acute psychiatric wards
}

\author{
Len Bowers · Henk Nijman • Alan Simpson • \\ Julia Jones
}

Received: 27 November 2008/Accepted: 5 January 2010/Published online: 16 January 2010

(C) The Author(s) 2010. This article is published with open access at Springerlink.com

\begin{abstract}
Background Conflict (aggression, substance use, absconding, etc.) and containment (coerced medication, manual restraint, etc.) threaten the safety of patients and staff on psychiatric wards. Previous work has suggested that staff variables may be significant in explaining differences between wards in their rates of these behaviours, and that structure (ward organisation, rules and daily routines) might be the most critical of these. This paper describes the exploration of a large dataset to assess the relationship between structure and other staff variables.

Methods A multivariate cross-sectional design was utilised. Data were collected from staff on 136 acute psychiatric wards in 26 NHS Trusts in England, measuring leadership, teamwork, structure, burnout and attitudes towards difficult patients. Relationships between these variables were explored through principal components analysis (PCA), structural equation modelling and cluster analysis.

Results Principal components analysis resulted in the identification of each questionnaire as a separate factor, indicating that the selected instruments assessed a number of non-overlapping items relevant for ward functioning. Structural equation modelling suggested a linear model in which leadership influenced teamwork, teamwork structure; structure burnout; and burnout feelings about difficult patients. Finally, cluster analysis identified two significantly distinct groups of wards: the larger of which had particularly good leadership, teamwork, structure, attitudes towards patients and low burnout; and the second smaller
\end{abstract}

L. Bowers $(\varangle) \cdot$ H. Nijman · A. Simpson · J. Jones City University, Philpot Street, London E1 2EA, UK e-mail: L.Bowers@city.ac.uk proportion which was poor on all variables and high on burnout. The better functioning cluster of wards had significantly lower rates of containment events.

Conclusion The overall performance of staff teams is associated with differing rates of containment on wards. Interventions to reduce rates of containment on wards may need to address staff issues at every level, from leadership through to staff attitudes.

Keywords Inpatients - Staff - Leadership - Teamwork · Burnout

\section{Background}

Difficult behaviours of patients on acute inpatient psychiatric wards represent a challenge to the staff, who strive to keep patients and others safe whilst they receive appropriate assessment and treatment for their psychiatric condition. Patients can be at risk of harming themselves, selfmutilating or on occasion attempting to commit suicide, they may abscond from the ward, be irritable and aggressive, break the normal social rules for appropriate behaviour or refuse to comply with necessary treatment. All these behaviours we collectively term 'conflict', and for some time we have been engaged in research to determine how staff can best act to reduce the frequency of such events. Psychiatric professionals use a range of means to prevent these behaviours, or the harmful outcomes that follow from them, ranging from the use of sedating medication, through special observation, to manual restraint, and in some places seclusion. We term these actions containment, and have been researching with the goal of finding ways to minimise both conflict and containment, whilst continuing to keep people safe [1]. 
Wards differ greatly from one another in their rates of conflict and containment. Our early research suggested that certain staff factors might influence these rates, for example the staff psychological understanding of patient behaviours, their moral commitments, how well they worked together as a team, and their production of an effective set of rules and routines for ward life (structure) [2]. We devised several research projects to further test this theory, including a longitudinal study, and a large multivariate study of 136 wards [3, 4]. The findings from these studies showed that it was the structure, the degree to which the wards were well ordered and organised, that had the closest relationship with conflict and containment rates. In the multivariate study, we had expected to find teamwork, leadership and feelings about difficult patients, to all show a relationship to optimum levels of conflict and containment. This did not occur, and instead we found a situation where these things were related to each other in a complex fashion. This paper presents the findings of an exploratory analysis to unravel these relationships, in order to clarify how they might be connected to conflict and containment rates on wards.

\section{Aim}

To understand the relationship between leadership, teamworking, structure, burnout and attitude to patients on acute psychiatric wards, and assess how that relates to rates of conflict and containment.

\section{Methods}

Sample

The sample comprised 136 acute psychiatric wards with their staff in 26 NHS Trusts in England, proximate to three regional centres during 2004-2005. The study was approved by the North West Multi-centre Research Ethics Committee.

\section{Instruments}

Questionnaires were distributed to staff on the wards over a 6-month period, to prevent overload of staff and enhance response. They were completed on an anonymous basis, so scores cannot be related to each other by individuals, only by ward. Five questionnaires are reported in this analysis: the attitude to personality disorder questionnaire (APDQ) [5]; ward atmosphere scale (WAS) [6]; team climate inventory (TCI) [7]; multifactor leadership questionnaire (MLQ) [8]; Maslach burnout inventory (MBI) [9]. The questionnaires chosen to represent features of the working model produced the following sub scores, which were entered in the analysis as mean scores by ward.

APDQ enjoyment (warmth and liking for, and interest in contact with patients); security (the lack of fear, anxiety and helplessness in relation to patients); acceptance (the absence of both anger towards patients and a sense of difference from them); purpose (feelings of meaning and purpose in working with patients); and enthusiasm (energy and absence of tiredness).

WAS order and organisation (how important order and organisation are in the program); program clarity (the extent to which patients know what to expect in their dayto-day routine and the explicitness of program rules and procedures); and staff control (the extent to which staff use measures to keep patients under necessary controls).

TCI participative safety (the degree to which the team meets regularly, all members share in decision making, individuals feel safe in making proposals, team members trust one another and participate fully in achieving the team's objectives); support for innovation (the degree to which articulated and enacted support is given for innovation, this is favoured over stability, and adequate resources given to the development of innovation); vision (the degree to which the team has a clear, shared, attainable vision/set of objectives which is valued by all team members); and task orientation (the degree to which the team is committed to achieving high performance, members critically appraise their work, and help in developing new ideas is available).

MLQ transformational leadership (the promotion of inspiration, intellectual stimulation, individual consideration, participative decision making and elective delegation); transactional leadership (the use of goal setting, feedback, reinforcement strategies, management by exception and laissez-faire leadership); and outcome of leadership (the degree to which the leader is viewed as effective and satisfactory, and obtains extra effort from staff).

MBI emotional exhaustion (feelings of being emotionally overextended and exhausted by work); depersonalisation (an unfeeling and impersonal response towards patients); and personal accomplishment (feelings of competence and successful achievement).

Data analysis

In total 6,661 questionnaires were collected and all analyses were conducted at the levels of wards. Therefore questionnaires were scored, and mean scores calculated for each of the 136 wards. Missing data on the questionnaires was minimal, and dealt with through mean imputation for missing items. However, response rates did vary by 
questionnaire (36-56\%) and by ward, so a minority of the ward scores are based upon small numbers of questionnaires. For one ward only one partially completed MLQ was returned, reducing the sample size by one for all analyses involving this scale. Three analyses of this dataset were conducted. First, a principal components analysis (PCA) was conducted to see if the scores could be reduced to a smaller number of factors. This type of analysis identifies underlying dimensions of a set of scores by assessing mathematically which scores tend to covary [10]. Second, factors from the PCA were entered into a structural equations modelling (SEM) specification search to identify the best fitting model of relationships [11]. Third, a cluster analysis was undertaken to assess where wards fitted well into a number of categorically distinct groups [12]. Finally, those ward groups were assessed for their relationship to conflict and containment by the use of $t$ tests. SPSS v16 and AMOS v7 were used for these analyses.

\section{Analysis 1: principal components analysis}

The numbers of questionnaires returned, the mean scores by ward, plus their individual response rates, are displayed in Table 1. The MBI was the first questionnaire to be distributed and obtained the highest response rate. The MLQ was both the last and the most sensitive questionnaire to be distributed, as it required respondents to judge their manager, and had the lowest response rate. Additional demographic information was collected together with the MBI, and indicated that the sample consisted mainly of qualified nurses (67\%) and healthcare assistants (29\%), with the majority being female $(66 \%)$, and of white British ethnicity $(68 \%)$.

The Kaiser-Meyer-Olkin measure of sampling adequacy was good at 0.76, and the Bartlett's test of sphericity was significant at $p<0.001$, both statistics indicating that the data had good properties for a principal components analysis. Varimax rotation was used, and the rotated component matrix is displayed in Table 2. Five components had eigenvalues greater than one, explaining $71 \%$ of the variance. Interestingly, each of these factors was equivalent to one of the five questionnaires that were distributed.

\section{Preliminary discussion}

While these results supply a rather elegant proof of the construct validity of the questionnaires as separate

Table 1 Response rates and scores (mean across ward scores) for the questionnaires

\begin{tabular}{|c|c|c|c|c|c|c|c|c|}
\hline & $n$ & Minimum & Maximum & Mean per ward & SD & $\begin{array}{l}\text { Mean \% of } \\
\text { total possible }\end{array}$ & Mean score & SD \\
\hline APDQ & 1,413 & 1 & 25 & 10.39 & 4.29 & 52 & & \\
\hline Enjoyment & & & & & & & 3.00 & 0.34 \\
\hline Security & & & & & & & 4.64 & 0.31 \\
\hline Acceptance & & & & & & & 4.78 & 0.32 \\
\hline Purpose & & & & & & & 4.23 & 0.43 \\
\hline Enthusiasm & & & & & & & 3.58 & 0.48 \\
\hline MBI & 1,525 & 2 & 25 & 11.21 & 4.67 & 56 & & \\
\hline Emotional exhaustion & & & & & & & 18.05 & 5.23 \\
\hline Depersonalisation & & & & & & & 5.55 & 2.21 \\
\hline Personal accomplishment & & & & & & & 35.77 & 3.06 \\
\hline MLQ & 981 & 1 & 24 & 7.27 & 3.85 & 36 & & \\
\hline Transformational & & & & & & & 12.77 & 2.42 \\
\hline Transactional & & & & & & & 6.39 & 1.01 \\
\hline Outcome & & & & & & & 8.15 & 1.56 \\
\hline TCI & 1,312 & 1 & 54 & 9.65 & 6.92 & 48 & & \\
\hline Participative safety & & & & & & & 3.70 & 0.38 \\
\hline Support for innovation & & & & & & & 3.50 & 0.38 \\
\hline Task orientation & & & & & & & 3.52 & 0.48 \\
\hline Vision & & & & & & & 3.59 & 0.42 \\
\hline WAS & 1,430 & 3 & 25 & 10.59 & 4.17 & 53 & & \\
\hline Order and organisation & & & & & & & 6.57 & 1.08 \\
\hline Program clarity & & & & & & & 6.59 & 0.96 \\
\hline Staff control & & & & & & & 1.76 & 0.76 \\
\hline
\end{tabular}


Table 2 Rotated component matrix

\begin{tabular}{|c|c|c|c|c|c|}
\hline & \multicolumn{5}{|c|}{ Component } \\
\hline & 1 & 2 & 3 & 4 & 5 \\
\hline MBI emotional exhaustion & & & & & 0.817 \\
\hline MBI depersonalisation & & & & & 0.813 \\
\hline \multicolumn{6}{|l|}{ MBI personal accomplishment } \\
\hline MLQ transformational leadership & & & 0.879 & & \\
\hline MLQ transactional leadership & & & 0.528 & & \\
\hline MLQ outcomes of leadership & & & 0.788 & & \\
\hline WAS order and organisation & & & & 0.756 & \\
\hline WAS program clarity & & & & 0.854 & \\
\hline \multicolumn{6}{|l|}{ WAS staff control } \\
\hline TCI participative safety & & 0.844 & & & \\
\hline TCI support for innovation & & 0.927 & & & \\
\hline TCI vision & & 0.813 & & & \\
\hline TCI task orientation & & 0.917 & & & \\
\hline APDQ enjoyment & 0.652 & & & & \\
\hline APDQ security & 0.755 & & & & \\
\hline APDQ acceptance & 0.857 & & & & \\
\hline APDQ purpose & 0.860 & & & & \\
\hline APDQ enthusiasm & 0.805 & & & & \\
\hline
\end{tabular}

Extraction method: principal components analysis. Rotation method: varimax with Kaiser normalization

conceptual entities, and of PCA as a mathematical method of finding underlying dimensions in data sets, these results did not assist in understanding the relationships between the questionnaires. They do demonstrate that the instruments each measure a specific, separate feature of ward team life. These results stress that investigating the relationships between these clearly separate characteristics of ward teams might be very helpful in revealing how these features interact and influence each other. The relevance is that with this uniquely large dataset, it can be empirically studied (for the first time) how style of leadership, and the way team members collaborate and interact with each other is associated with negative outcomes such as burnout of staff members, feelings of insecurity and a lack of enjoyment in working with the patients.

\section{Analysis 2: structural equation modelling to find the best fitting model}

Factor scores from the preceding analysis were used to conduct a specification search to identify the best fitting model of relationships between them. A path diagram was constructed in which each variable was connected to every other in both directions. The software was then used to identify which of over one million potential models best fitted the data, using a range of fit statistics. This
Fig. 1 Best fitting model of relationships between the questionnaires, as yielded by a structural equation model specification search (with standardised regression weights)

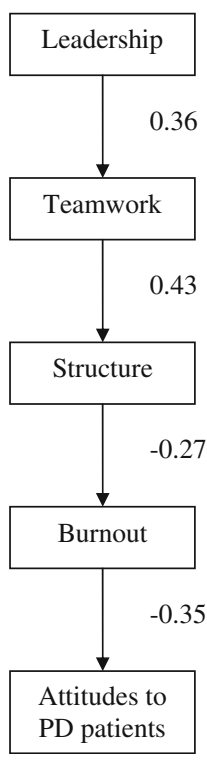

exploratory procedure is to facilitate theory building rather than confirm causal connections.

Six models were identified as having a particularly good fit. The first included a number of bi-directional relationships, and was rejected on the grounds that the other models were simpler and more parsimonious. The remaining five models had all variables in the same orderly linear relationships, but with those relationships in varying directions. These models all had the same degree of fit to the data (Brown and Cudeck criterion $=4.92$, Bayes information criterion $=0.00$ ). On the criteria that leadership was more likely to influence teamwork than the other way round, all models but one were excluded, and this final model is displayed in Fig. 1, with standardised regression weights. Thus, the direction of influence seems most likely to flow from leadership, through teamwork, structure and burnout to attitudes towards difficult patients. The variables next to each other are more greatly influenced by the preceding variable in the chain, the further apart the weaker the influence. For example, leadership has a strong, 36\% influence over teamwork, but only a $4 \%$ influence over burnout (through teamwork and structure) and a $1 \%$ influence over attitudes to personality disordered patients.

\section{Preliminary discussion}

This model neatly depicts a linear sequence of relationships between the staff variables collected during the study. It suggests some interesting leverage points for producing change. For example, if reducing burnout in the staff team is desired, interventions based upon building a ward structure are likely to be more effective than interventions to improve the functioning of the team leader. Moreover, this link between collective social action (structure) and 
positive 'emotional effervescence' (absence of burnout) receives considerable support in the sociological literature dating back to the seminal work of Durkheim $[13,14]$.

\section{Analysis 3: cluster analysis}

The SPSS two-step cluster analysis procedure was used to classify wards into distinct groups based on their factor scores as identified in analysis one. Using the Bayes information criterion as a measure, this procedure reliably identifies two clusters as a best fit for the data, one larger cluster of 78 wards with good leadership, teamwork, structure, positive attitudes to difficult patients and low burnout, and one smaller cluster of 56 wards with more negative scores for all these features. When contrasted using $t$ tests, the better functioning wards used fewer containment methods ( 9 vs. $11, t=2.61, p=0.010$, $n=136$ ), but were not significantly different in their mean number of conflict events per day (14 vs. $15, t=1.49$, $p=0.136, n=136$ ).

\section{Final discussion}

By means of exploring the associations in this dataset consisting of 6,661 questionnaires from staff on 136 psychiatric acute admission wards in the UK, we arrived at a model of relationships between the different features of the staff team and its functioning. This model has a good fit to the data and substantial face validity. Leadership impacts on teamwork, teamwork impacts on structure, structure influences burnout, and burnout influences attitudes towards difficult patients. The way the staff function as a team and have clarity amongst themselves about ward organisation and the ward program may thus be influential in preventing burnout and exhaustion of the staff. The style and efficacy of leadership, interestingly, does not show much direct relation to feelings of burnout, although previous healthcare research has shown a relationship to job satisfaction [15]. The relatively slight influence of leadership may be specific to ward nursing teams. Leadership in such teams is distributed across a number of people, including: the ward manager (the person rated in this project), consultant psychiatrist(s), senior qualified nurses who are in charge of shifts when on duty, and managers at a higher level than ward staff in several layers up to the top management team of the healthcare organisation. In addition, the shift system means that the nursing team never meets as a whole with the ward manager, and communication downwards is easily fractured. This may well be why staff having clarity among themselves about the ward organisation and rules may be so central in the resulting model.
The variable previously shown by our research to be most strongly related to rates of conflict and containment on the ward is structure [4]. The greater the structure, the lower the rates of conflict and containment on the ward [16]. Our structural equation model therefore implies that leadership and teamworking will also impact on conflict and containment, through their positive association with greater structure. This is partly supported by our cluster analysis findings, in that the better functioning wards on all staff measures used two less containment measures per day (10\% fewer).

What is clear from the model is that it is teamwork that is critical to the production of structure. In recent years there has been a substantial investment in leadership courses for ward managers on acute inpatient wards in the UK, in part to address perceived deficits [17]. The efficacy of leadership training is not rigorously proven, with what published work there is relying on small samples and self report questionnaires completed by course attenders, rather than hard performance-related outcomes [18, 19]. Our findings suggest that insofar as burnout as well as conflict and containment rates on the ward are concerned, a better investment might be made by striving to improve teamwork. However, the efficacy of interprofessional team development [20] also remains unknown.

Cluster analysis suggests two systemic positions of the ward nursing team: a well functioning position (albeit with variations in the relative strength of leadership, teamworking, structure, etc.); and a dysfunctional position with deficits across the board. This raises interesting questions about how the more optimum position can be attained and maintained, or what can be done to remedy wards operating in a dysfunctional way. The structural equation model suggests that a simple change of ward manager may be, by itself, a relatively weak intervention that takes some time to have an effect through raising the quality of teamwork. A more effective intervention may be to change nearly all the staff on a ward (through rotation to other areas), thus enabling more radical cultural change. However, it might still remain the case that poor leadership might retard the development of a well-functioning team. Alternatively, and perhaps less confidence sapping for those working on the ward, would be to target interventions at every level: leadership training for the ward manager, team building interventions for the team, ward rule and routine clarification and agreement to strengthen structure, and clinical supervision to reduce burnout and enhance positive attitudes to difficult patients.

Ward managers could themselves utilise this combination of measures in order to strengthen the impact of their leadership role. The implications for team members is that they may be able to reduce their own vulnerability to burnout and negative attitudes towards patients by participating in and facilitating open, creative communication; listening and 
responding to fellow team members; contributing to and supporting a shared vision; and supporting consistency and a commonly agreed structure to ward life for patients. In combination, it would appear that ward teams can make a significant difference to themselves, and to the patient experience, especially in reducing containment use.

It is important to realise that throughout the analyses in this paper we have been dealing with notional group properties of the whole staff team. This is most likely to be robust for those questionnaires where all respondents are rating the same thing, that is: team climate, ward atmosphere, or the team's leader. Where they are rating their own emotional states, as with attitude to personality disorder or burnout, these scores are likely to be more diverse, being determined by individual factors such as personality, past history, individual experience of training and the like. The degree to which such scores can be aggregated to the team level is more questionable [21], as there is sometimes as much variation within teams as between them. Nevertheless, these results did show meaningful relationships with each other and with other variables, and clustered by questionnaire in the factor analysis, suggesting that our analyses had merit. However, it is possible that at the individual level relationships between the questionnaires might be different, as the scores would then represent individual perceptions of leadership and teamwork, rather than multiple (and hence more reliable) ratings of those same things. Additionally, the analyses we have conducted with our data are exploratory rather than confirmatory. As such they are intended to contribute to theory development. Further work on new samples is required in order to make these findings secure.

\section{Conclusions}

Our data have the best fit with a model where structure is most strongly determined by teamworking, and to a lesser extent by good leadership. As we know that structure is the factor most strongly associated with conflict and containment rates, this implies that to assist wards in establishing and maintaining an effective structure for patients, will require an intervention that enhances leadership and supports and builds the ward team and its functioning.

Acknowledgments This research was funded by the National Institute of Health Research Service Delivery and Organisation Programme. However, the views expressed in this publication are those of the authors and not necessarily those of the funding body. The funding body approved the design of the study, and received regular reports on the data collection. Although other results of this study have been subject to peer review arranged by the study funding body, the analysis reported here has not. The funding body has received an advance copy of this manuscript, but is not entitled to require, nor has requested, any alterations.
Conflict of interest statement The author has no conflict of interest to declare, nor does he have any relevant financial interest in this manuscript.

Open Access This article is distributed under the terms of the Creative Commons Attribution Noncommercial License which permits any noncommercial use, distribution, and reproduction in any medium, provided the original author(s) and source are credited.

\section{References}

1. Bowers L (2006) On conflict, containment and the relationship between them. Nurs Inq 13(3):172-180

2. Bowers L (2002) Dangerous and severe personality disorder: response and role of the psychiatric team. Routledge, London

3. Bowers L, Whittington R, Nolan P et al (2007) The city 128 study of observation and outcomes on acute psychiatric wards. Report to the NHS SDO Programme. NHS SDO Programme, London

4. Bowers L, Hackney D, Nijman $\mathrm{H}$ et al (2007) A longitudinal study of conflict and containment on acute psychiatric wards. Report to the Department of Health. City University, London

5. Bowers L, Allan T (2006) The attitude to personality disorder questionnaire: psychometric properties and results. J Personal Disord 20:281-293

6. Moos R (1974) Ward atmosphere scale manual. Consulting Psychologists Press, Palo Alto, CA

7. Anderson N, West M (1999) Team climate inventory (TCI): user's guide. NFER-NELSON Publishing, Windsor

8. Bass B, Avolio B (1995) Multifactor leadership questionnaire. Mind Garden, Redwood City, CA

9. Maslach C, Jackson S (1981) The Maslach burnout inventory. Consulting Psychologists Press, Palo Alto, CA

10. Kline P (1993) An easy guide to factor analysis. Routledge, London

11. Hair J, Anderson R, Tatham R et al (1998) Multivariate data analysis. Prentice-Hall, New Jersey

12. Everitt B, Landau S, Leese M (2001) Cluster analysis. Arnold, London

13. Durkheim E (1912) The elementary forms of religious life. Free Press, New York

14. Collins R (2004) Interaction ritual chains. Princeton University Press, Princeton, NJ

15. Borrill C, West M, Dawson J (2003) The relationship between leadership and trust performance. Aston Business School, Birmingham

16. Bowers L (2007) Multivariate testing of a model of staff factors in the determination of levels of conflict and containment on acute psychiatric wards. Psychiatric Services

17. Department of Health (2002) Mental health policy implementation guide. Adult acute inpatient care provision. Department of Health, London

18. Garland G (2003) Building on the success of LEO. Nurs Manag $10: 16-18$

19. Hancock H, Campbell S, Bignell P et al (2005) The impact of leading empowered organisations (LEO) on leadership development in nursing. Int J Health Care Qual Assur 18:179-192

20. Reeves S, Freeth D (2006) Re-examining the evaluation of interprofessional education for community mental health teams with a different lens: understanding presage, process and product factors. J Psychiatr Mental Health Nurs 13:765-770

21. Garman A, Corrigan P, Morris S (2002) Staff burnout and patient satisfaction: evidence of relationships at the care unit level. J Occup Health Psychol 7:235-241 